\title{
Estimation of Endocarpon pusillum Hedwig carbon budget in the Tengger Desert based on its photosynthetic rate
}

\author{
DING LiPing ${ }^{1,2}$, ZHOU QiMing $^{1} \&$ WEI JiangChun ${ }^{1 *}$ \\ ${ }^{1}$ State Key Laboratory of Mycology, Institute of Microbiology, Chinese Academy of Sciences, Beijing 100101, China; \\ ${ }^{2}$ University of Chinese Academy of Sciences, Beijing 100049, China
}

Received April 18, 2013; accepted June 20, 2013; published online July 31, 2013

\begin{abstract}
This study investigated the photosynthetic rate of the lichen Endocarpon pusillum at the Chinese Academy of Sciences Shapotou Desert Research Station and estimated its annual contribution to the carbon budget in the ecosystem. The software SigmaPlot 10.0 with "Macro-Area below curves" was used to calculate the carbon fixation capacity of the lichen. The total carbon budget $(\Sigma \mathrm{C})$ of the lichen was obtained by subtracting the respiratory carbon loss ( $\Sigma \mathrm{DR})$ from the photosynthetic carbon gain $(\Sigma N P)$. Because water from precipitation plays an important role in photosynthesis in this ecosystem, the annual carbon budget of E. pusillum at the station was estimated based on the three-year average precipitation data from 2009 to 2011. Our results indicate that the lichen fixes $14.6 \mathrm{~g} \mathrm{C} \mathrm{m}^{-2}$ annually. The results suggest that artificial inoculation of the crust lichen in the Tengger Desert could not only help reduce the sand and dust storms but also offer a significant carbon sink, fixing a total of $438000 \mathrm{t}$ of carbon over the $30000 \mathrm{~km}^{2}$ of the Tengger Desert. The carbon sink could potentially help mitigate the atmospheric greenhouse effect. Our study suggests that the carpet-like lichen E. pusillum is an excellent candidate for "Bio-carpet Engineering" of arid and semi-arid regions.
\end{abstract}

crust organisms, carpet-like lichen, carbon income, carbon loss, carbon sink

Citation: Ding L P, Zhou Q M, Wei J C. Estimation of Endocarpon pusillum Hedwig carbon budget in the Tengger Desert based on its photosynthetic rate. Sci China Life Sci, 2013, 848-855, doi: 10.1007/s11427-013-4526-9

The vegetation for sand control planted since 1956 in the Shapotou region of the Tengger Desert in northwest China has led to high soil water loss in the region [1-3]. The changes in soil water content were observed 10 years after the artificial vegetation was planted [4]. By contrast, ecological niches with native crust microbial communities showed little change in their soil water content [5]. In addition, these crust microbial communities have helped stabilize the sands, with relatively few incidences of sand and dust storms [6]. This suggests that carpet-like crust microbial communities can be used to maintain and revitalize the water balance of arid and semi-arid regions, via a process called "Bio-carpet Engineering" [7].

*Corresponding author (email: weijc2004@126.com)
Microbiotic crusts consisting of bacteria, fungi, algae, lichens, and bryophytes colonize most terrestrial surfaces, especially in arid and semi-arid regions. These crust microbial communities are able to fix carbon and nitrogen from the atmosphere [8]. This enriches the fertility of the sand and soil, reduces sand and dust storms, and potentially contributes to mitigating the atmospheric greenhouse effect. Of the various crust organisms, lichens are usually the most common.

A lichen is a symbiotic association of a fungus (mycobiont) and a photosynthetic partner (photobiont), which may be an alga (phycobiont) or a cyanobacterium (cyanobiont). The association is a complicated arrangement in which the fungus produces a thallus, or body, within which the photobionts are housed [9]. 
Therefore, the lichen-forming fungi together with photosynthetic algae and/or cyanobacteria in symbioses as lichens appear to function like a single autotrophic "organism" [10]. The relationship is a relatively stable and well-balanced symbiotic association containing both heterotrophic and autotrophic components. Indeed, the lichen can be regarded as a self-contained miniature ecosystem [11-13].

In lichens, carbohydrate acquisition is directly related to photosynthesis performed by the photobionts algae or cyanobacteria, while minerals and water are acquired through the thallus. Since mycobiont hyphae almost always make up the dominant part of the lichen biomass, it is reasonable to assume that the fungal hyphae acquire most of the water and minerals, similar to the functions of roots in plants. However, unlike plant roots, the cyanobacteria in lichens can fix nitrogen, converting $\mathrm{N}_{2}$ to $\mathrm{NH}_{3}$. In addition, polyols, the secondary carbon metabolites, and cell walls of lichens have been proposed as major carbon sinks [14].

The photosynthetic and respiratory $\mathrm{CO}_{2}$ exchange rates of three soil-crust lichens, Acarospora cf. schleicheri, Caloplaca volkii and Lecidella crystallina have been measured in the Namib Desert in South Africa. When experimentally exposed to optimal conditions of light and hydration, the lichen soil crusts in the Namib Desert showed a photosynthetic potential almost equal to that of higher plant leaves [15]. The potential carbon sinks offered by the carpet-like lichens covering arid and semiarid deserts can make a positive contribution to mitigating the atmospheric greenhouse effect.

In this preliminary study of a "Bio-carpet Engineering" project using the carpet-like lichens to control the spread of sandy deserts, the photosynthetic rate of the lichen Endocarpon pusillum was measured at the Chinese Academy of Sciences (CAS) Shapotou Desert Research Station (SDRS) which is located in the Ningxia Hui Automonous Region on the southeast edge of the Tengger Desert at $37^{\circ} 32^{\prime} \mathrm{N}$ and $105^{\circ} 02^{\prime} \mathrm{E}$ with an elevation of $1339 \mathrm{~m}$. The mean annual air temperature is $10.0^{\circ} \mathrm{C}$ with a recorded minimum temperature of $-25.1^{\circ} \mathrm{C}$ and maximum temperature of $38.1^{\circ} \mathrm{C}$. The annual sunlight exposure is $3264 \mathrm{~h}$; the mean annual precipitation is $180.2 \mathrm{~mm}$, and the annual evaporation is $3000 \mathrm{~mm}$. These values place this region in the arid desert zone [16-18].

The lichen E. pusillum is one of the dominant species among the crust organisms at the CAS SDRS. However, the potential carbon sink offered by the lichen and its contribution to the global cycles of carbon have not yet been quantified. In this study, the field measurements of the photosynthetic rate of the lichen at the CAS SDRS were performed and its potential carbon fixation was calculated.

\section{Materials and methods}

\subsection{Materials}

Fresh samples of the lichen E. pusillum for the laboratory measurements were collected from the SDRS $2 \mathrm{~d}$ before measurements. Its phycobiont Diplosphaera chodatii Bialosuknia [19] was isolated from the hymenial algal cells of the lichen. The strain of D. chodatii for the study is permanently stored in Centre for General Microbiological Culture Collection (CGMCC), and the specimen of the lichen $E$. pusillum is kept in Herbarium Mycologicum Academiae Sinicae (HMAS-L). Field measurements of E. pusillum photosynthetic rates were conducted at the CAS SDRS.

\subsection{Chlorophyll extraction for quantification}

The photosynthesis of the lichen E. pusillum is performed by its phycobiont partner. Therefore, comparison of the photosynthetic rates between the lichen E. pusillum and its phycobiont $D$. chodatii is necessary. Here we will start with quantifying chlorophylls from both the lichen and the alga.

For this test, the phycobiont was maintained in an axenic liquid culture in $300 \mathrm{~mL}$ of Bold's Basal Medium [20] in an Erlenmyer flask and incubated in a shaking incubator (BHWY-2112, Safe, Ningbo, Zhejiang, China) with illumination. Conditions of $130 \mathrm{r} \mathrm{min}^{-1}$ at $20^{\circ} \mathrm{C}$ under $2000 \mathrm{~lx}$ were maintained for three months. The liquid culture of the phycobiont was centrifuged at $200 \times g$ for $5 \mathrm{~min}$. The supernatant was discarded and $200 \mu \mathrm{L}$ of the phycobiont $D$. chodatii suspension from the precipitate $(8 \mathrm{~mL})$ was transferred to a $5 \mathrm{~mL}$ centrifuge tube. A $1 \mathrm{~cm}^{2}$ piece of the E. pusillum was transferred into a separate $5 \mathrm{~mL}$ centrifuge tube.

Chlorophyll extraction was performed with dimethyl sulfoxide (DMSO) [21]. Four milliliter of DMSO was added to centrifuge tubes containing either $D$. chodatii or the lichen E. pusillum. The tubes were placed in a water bath at $65^{\circ} \mathrm{C}$ for $40 \mathrm{~min}$ to extract the chlorophyll. The extracts were centrifuged at $300 \times g$ for $1.5 \mathrm{~min}$. The supernatants were scanned with an ultraviolet spectrophotometer (DU-800) between the wavelengths of 400-700 nm with a slit of $1 \mathrm{~nm}$. The absorption peaks of the chlorophyll of both the E. pusillum and $D$. chodatii were very similar: 2.4 at $435 \mathrm{~nm}$ and 1.4 at $665 \mathrm{~nm}$. The result indicates that the chlorophyll content in $1 \mathrm{~cm}^{2}$ of the lichen E. pusillum is equal to that in the phycobiont $D$. chodatii suspension of $200 \mu \mathrm{L}$. Each experiment was repeated three times.

\subsection{Laboratory measurement of $E$. pusillum and $D$. chodatii photosynthetic rates}

For comparison, the photosynthetic rates based on $\mathrm{CO}_{2}$ exchange in the green algal lichen E. pusillum and its phycobiont $D$. chodatii were measured. $\mathrm{CO}_{2}$ exchange was measured under controlled conditions with a Handheld Photosynthesis System CI-340 (CID Bio-Science, Inc., USA). A fresh sample of the lichen E. pusillum was collected from the CAS SDRS $2 \mathrm{~d}$ before measurement. Ten square centimeters of water-saturated lichen was placed on a watersaturated soil layer in a leaf chamber of $10 \mathrm{~cm}^{2}$. For the 
phycobiont, a $2 \mathrm{~mL}$ suspension of cells prepared as described above was spread onto a thin sand layer in another leaf chamber. The saturated lichen was sprayed with water equivalent to $>2 \mathrm{~mm}$ of precipitation.

The measurements of both the lichen E. pusillum and its phycobiont $D$. chodatii were carried out at temperatures of $5^{\circ} \mathrm{C}, 20^{\circ} \mathrm{C}$ and $30^{\circ} \mathrm{C}$, and under red light intensities of 0,100 , 200, 400, 800, 1200, 1600, 2000 and $2400 \mu \mathrm{mol} \mathrm{m} \mathrm{m}^{-2} \mathrm{~s}^{-1}$ gradient, and $\mathrm{CO}_{2}$ concentration of $600 \pm 50$ ppm. Each experiment was repeated three times.

The respiratory rate of E. pusillum in the dark was also measured under the conditions simulated the field conditions.

\subsection{Field measurements of $E$. pusillum photosynthetic} rates

$\mathrm{CO}_{2}$ exchange in the field was measured under natural conditions with a Handheld Photosynthesis System CI-340 (CID Bio-Science, Inc., USA) at the CAS SDRS. The four different vegetation zones at the CAS SDRS contain crusts of different ages. The eldest crust is in the 1956 artificial vegetation zone, and the youngest one in the 1990 zone. Measurement of E. pusillum photosynthetic rates was conducted in the 1956 artificial vegetation zone.

A $10 \mathrm{~cm}^{2}$ area was transferred to the leaf chamber for measurement. The leaf chamber was not enclosed after each measurement, so the $\mathrm{CO}_{2}$ concentration in the chamber was equal to that in the atmosphere. Each sample was measured for $2 \mathrm{~min}$ and repeated an average of three times per hour. The field measurements were typically conducted from 5:00 a.m. to 8:00 p.m. of June 30-July 8, October 25-November 9 in 2010, and April 5-16, December 26-28 in 2011.

\subsection{Estimated carbon budget of $E$. pusillum in the field}

The carbon budget $(\Sigma \mathrm{C})$ of $E$. pusillum lichen crust was obtained by subtracting the respiratory carbon loss $(\Sigma \mathrm{DR})$ from the photosynthetic carbon income $(\Sigma \mathrm{NP})(\Sigma \mathrm{C}=\Sigma \mathrm{NP}-$ $\Sigma D R$ ) [22]. SigmaPlot 10.0 software with "Macro-Area below curves" was used to calculate the $\Sigma \mathrm{C}$. Because water availability has a large influence on both photosynthesis and respiration, the $\Sigma \mathrm{C}$ of the lichen per year was calculated and estimated based on the mean annual precipitation from 2009 to 2011 (Figure 1).

\section{Results and discussion}

2.1 The photosynthetic rates of $E$. pusillum and $D$. chodatii in the laboratory

All experiments were performed under optimal moisture conditions. The results demonstrated that the respiratory rates of both the $D$. chodatii and E. pusillum were between 0 and $-1 \mu \mathrm{mol} \mathrm{m} \mathrm{m}^{-2}$ at $5^{\circ} \mathrm{C}$. The light saturation points (LSP) for E. pusillum and D. chodatii were 1200 and 400 $\mu \mathrm{mol} \mathrm{m} \mathrm{m}^{-2} \mathrm{~s}^{-1}$, respectively. The maximum net photosynthetic rate $(P n)$ for $D$. chodatii was $2.8 \mu \mathrm{mol} \mathrm{m}{ }^{-2} \mathrm{~s}^{-1}$, slightly higher than that for E. pusillum, which was $1.2 \mu \mathrm{mol} \mathrm{m}^{-2} \mathrm{~s}^{-1}$ (Figure 2A).

The respiratory rate of E. pusillum was $-6.5 \mu \mathrm{mol} \mathrm{m}{ }^{-2} \mathrm{~s}^{-1}$, lower than that of D. chodatii $\left(-1.6 \mu \mathrm{mol} \mathrm{m} \mathrm{m}^{-2} \mathrm{~s}^{-1}\right)$ at $20^{\circ} \mathrm{C}$. The LSPs for E. pusillum and D. chodatii were 1600 and $1200 \mu \mathrm{mol} \mathrm{m} \mathrm{s}^{-2}$, respectively. At $20^{\circ} \mathrm{C}$, the maximum $P n$ for $E$. pusillum and D. chodatii were 3.5 and $6.1 \mu \mathrm{mol} \mathrm{m}^{-2} \mathrm{~s}^{-1}$, higher than the maximum values at $5^{\circ} \mathrm{C}$ (Figure $2 \mathrm{~B}$ ).

The respiratory rate of E. pusillum was $-11.0 \mu \mathrm{mol} \mathrm{m} \mathrm{m}^{-2} \mathrm{~s}^{-1}$, much lower than that of $D$. chodatii $\left(-4.4 \mu \mathrm{mol} \mathrm{m}{ }^{-2} \mathrm{~s}^{-1}\right)$ at $30^{\circ} \mathrm{C}$. The LSPs for E. pusillum and D. chodatii were 2400 and $2000 \mu \mathrm{mol} \mathrm{m}{ }^{-2} \mathrm{~s}^{-1}$, respectively. The maximum $P n$ for the lichen was only $1.5 \mu \mathrm{mol} \mathrm{m} \mathrm{m}^{-2} \mathrm{~s}^{-1}$, close to that at $5^{\circ} \mathrm{C}$, but significantly lower than that at $20^{\circ} \mathrm{C}$; and the $P n$ for the phycobiont was $5.9 \mu \mathrm{mol} \mathrm{m} \mathrm{m}^{-2} \mathrm{~s}^{-1}$, similar to that at $20^{\circ} \mathrm{C}$ (Figure 2C).

The results showed that the $P n$ of the phycobiont D. chodatii was always higher than that of the lichen

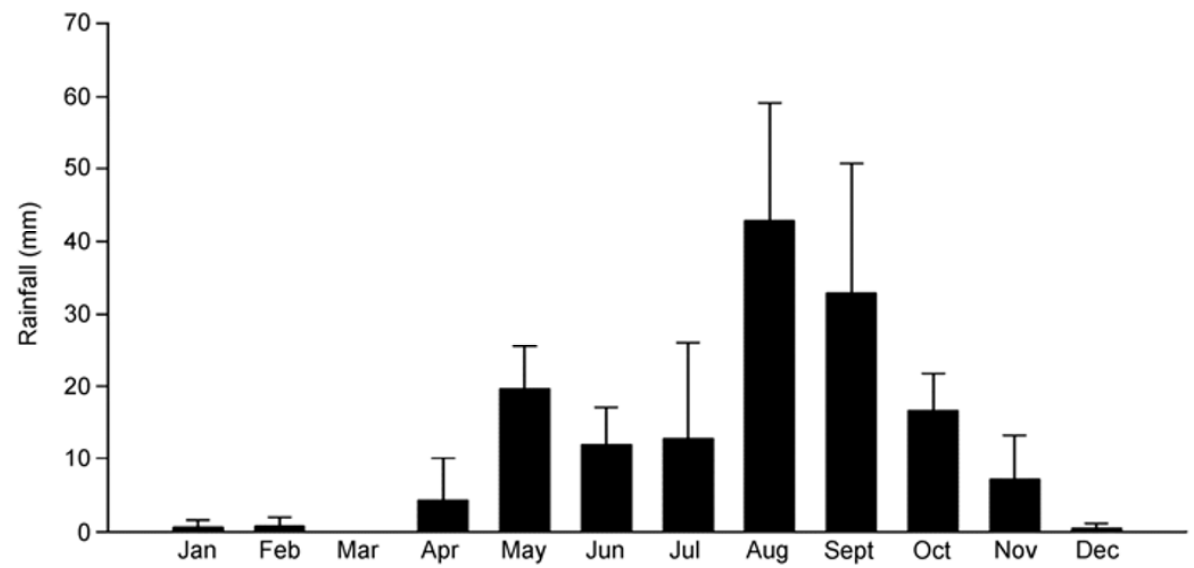

Figure 1 Average monthly rainfall at the CAS SDRS during 2009-2011. 
E. pusillum, while the respiratory rate of the phycobiont always lower than that of the lichen at all three temperatures. This can be explained by the fact that the photosynthetic rate of both the lichen E. pusillum and the phycobiont $D$. chodatii is performed by $D$. chodatii only, but both the mycobiont $E$. pusillum and the phycobiont $D$. chodatii contribute to E. pusillum's respiratory rate.

\subsection{Field measurements of $E$. pusillum photosynthetic rates and carbon budget calculation}

\subsubsection{The results of measurements in 2010}

The results of the daytime measurements of the photosyn- thetic rate of the lichen during the 25 days from June 30 to July 8, and from October 25 to November 9 in 2010 at the CAS SDRS indicated that both the respiratory rate (in early morning) and the net photosynthetic rate increased after rainfall (Figure 3).

Our results showed that in the early morning after a rainfall event on June 30, 2010, the respiratory rate reached $-6.3 \mu \mathrm{mol} \mathrm{m} \mathrm{m}^{-2} \mathrm{~s}^{-1}$, the lowest rate measured in the field. The $P n$ increased gradually after 8:00 a.m. and reached a maximum value of $4.8 \mu \mathrm{mol} \mathrm{m} \mathrm{m}^{-2} \mathrm{~s}^{-1}$ at 11:00 a.m. After 11:00 a.m. the $P n$ declined gradually and reached zero at 1:00 p.m. In the late afternoon, the $P n$ became negative and the respiratory rate declined to $-3.0 \mu \mathrm{mol} \mathrm{m} \mathrm{m}^{-2} \mathrm{~s}^{-1}$ owing to

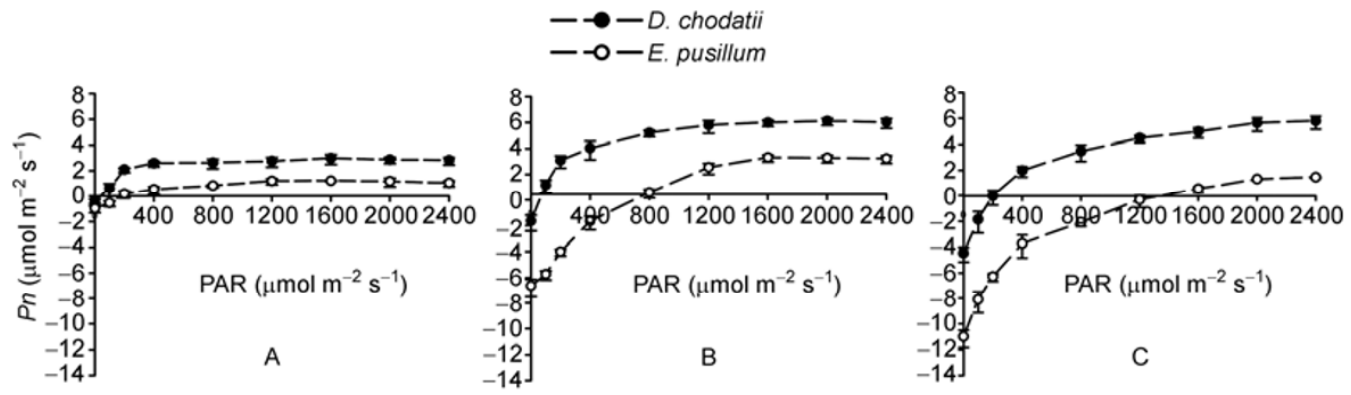

Figure 2 Response of net photosynthetic rate $(P n)$ ) to photosynthetic active radiation (PAR) for both E. pusillum and its phycobiont $D$. chodatii, as measured at $5^{\circ} \mathrm{C}(\mathrm{A}), 20^{\circ} \mathrm{C}(\mathrm{B}), 30^{\circ} \mathrm{C}(\mathrm{C})$ and optimal moisture conditions in the laboratory.

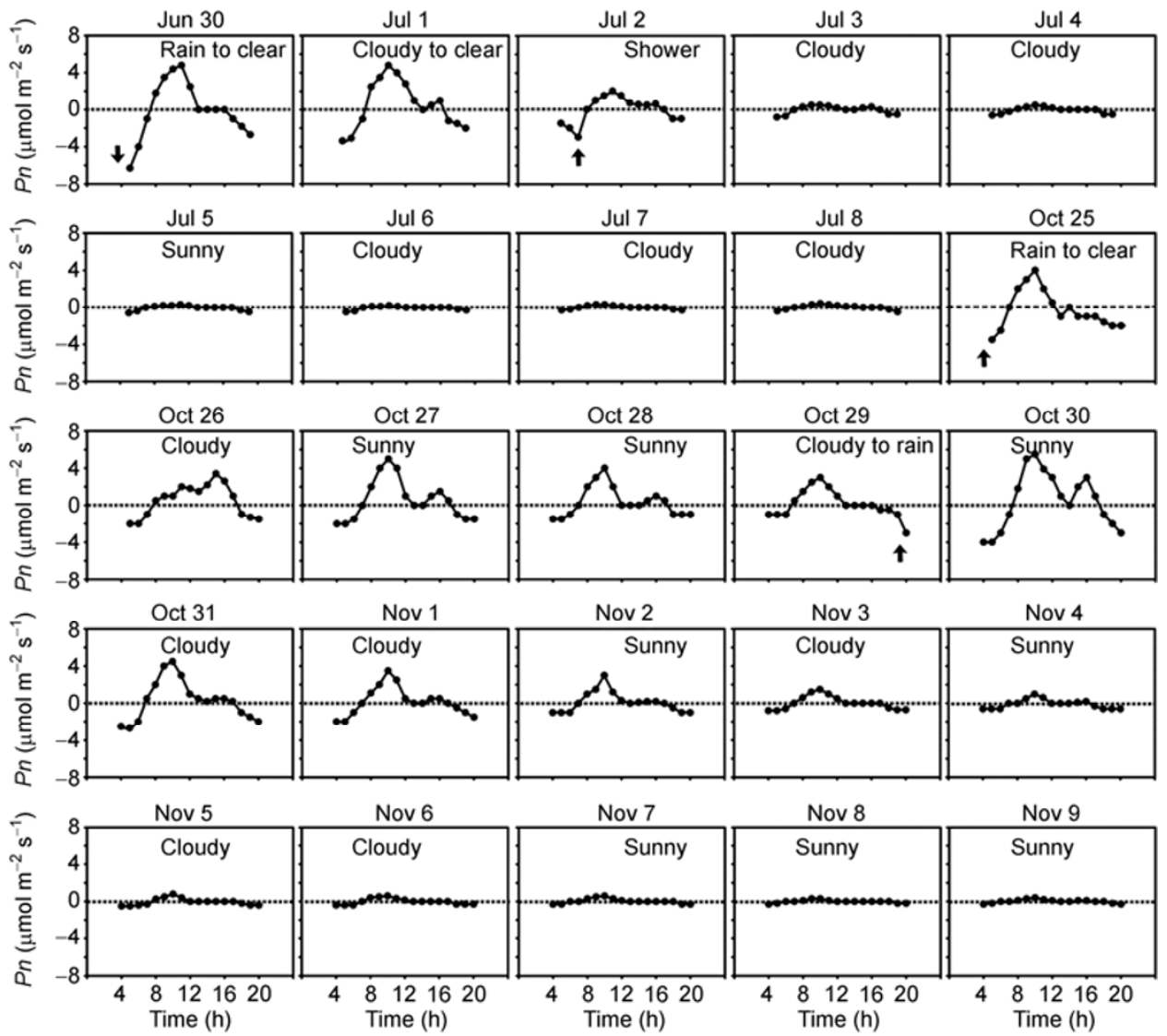

Figure 3 Field observations of the net photosynthetic rate $(P n)$ of Endocarpum pusillum, at the CAS SDRS over a period of 25 days from June 30 to July 8 , and from October 25 to November 9 in 2010. The arrows indicate rainfall events. 
the decreased light intensity. A similar result was observed during July 1-2, October 25-31, and November 1-4 (Figure 3 ). The $P n$ values of E. pusillum were close to zero in the days without any rain and the lichen thallus was almost dry.

Photosynthetic carbon fixation was calculated based on the $P n$ data from 5:00 a.m. to 8:00 p.m. (4:00 a.m.-8:00 p.m., Oct. 26-Nov. 9) on each day (Figure 3). The software SigmaPlot 10.0 was used to quadrature the difference between the upper abscissa area and the down area of the $P n$ curve. The results were then converted into mg C (Figure 4).

After rainfall of $5 \mathrm{~mm}$ in the summer of 2010, the carbon assimilation was $201 \mathrm{mg} \mathrm{m}^{-2}$ on June 30 and $319.7 \mathrm{mg} \mathrm{m}^{-2}$ on July 1 . Although there was $0.5 \mathrm{~mm}$ rainfall on July 2 , the carbon intake was $99.4 \mathrm{mg} \mathrm{m}^{-2}$. The amount of carbon fixation was approximately $30.0 \mathrm{mg} \mathrm{m}^{-2}$ during the six cloudy and sunny days from July 3 to 8 (Figure 4). The total carbon assimilation of the lichen is estimated to be $650 \mathrm{mg} \mathrm{m}^{-2}$ for the period of the nine days from June 30 to July 8 of 2010
(Figure 4).

It rained on October 25 and 29 and the carbon fixation was positive in the next nine days from October 26 to November 3 except October 25 because of the greater respiratory rate. The highest peak $\left(505.4 \mathrm{mg} \mathrm{m}^{-2}\right)$ of the carbon income was on October 30. Carbon sequestration became negative $\left(-73.1 \mathrm{mg} \mathrm{m}^{-2}\right)$ on November 4 . The total carbon assimilation of the lichen is estimated to be $2174 \mathrm{mg} \mathrm{m}^{-2}$ during the period from October 25 to November 9 of 2010, which included two rainy days (Figure 4).

\subsubsection{Field results in 2011}

The results of the daytime measurement of the photosynthetic rate of the lichen during the 15 days from April 5 to 16, and from December 26 to 28 in 2011 at the CAS SDRS showed that the $P n$ was almost zero throughout the tested periods because of the lack of precipitation, except for the rainfall event on April 5 (Figure 5).

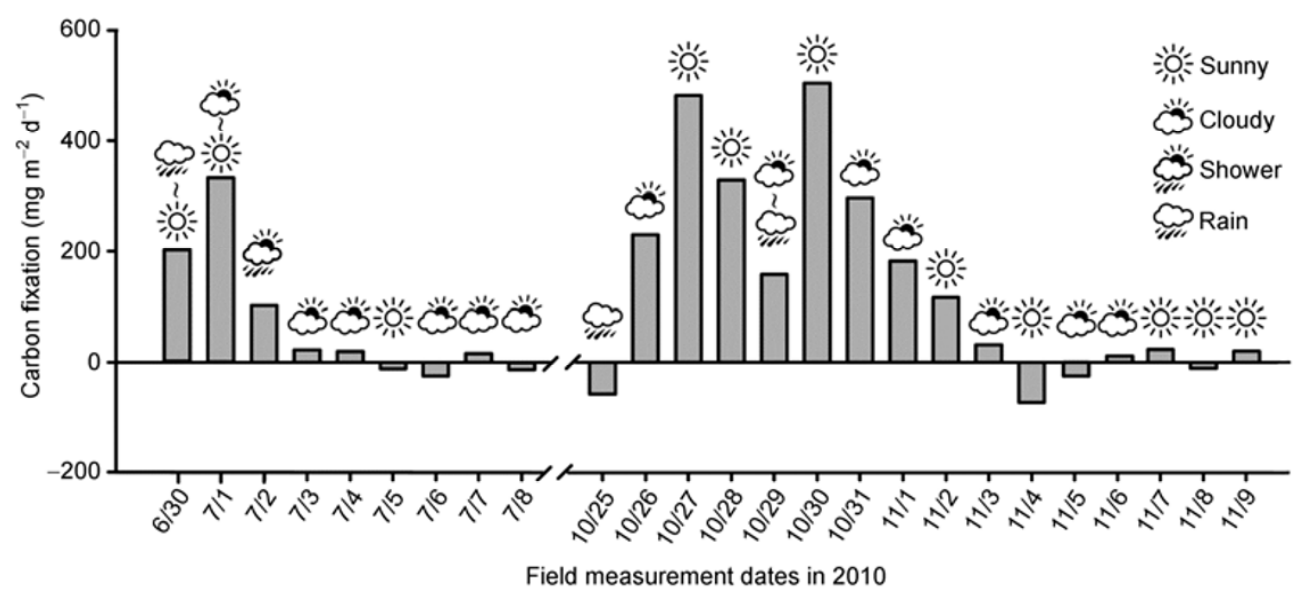

Figure 4 Field measurements of Endocarpon pusillum's diel photosynthetic carbon income over the period June 30-July 8, October 25-November 9, 2010 at the CAS SDRS.

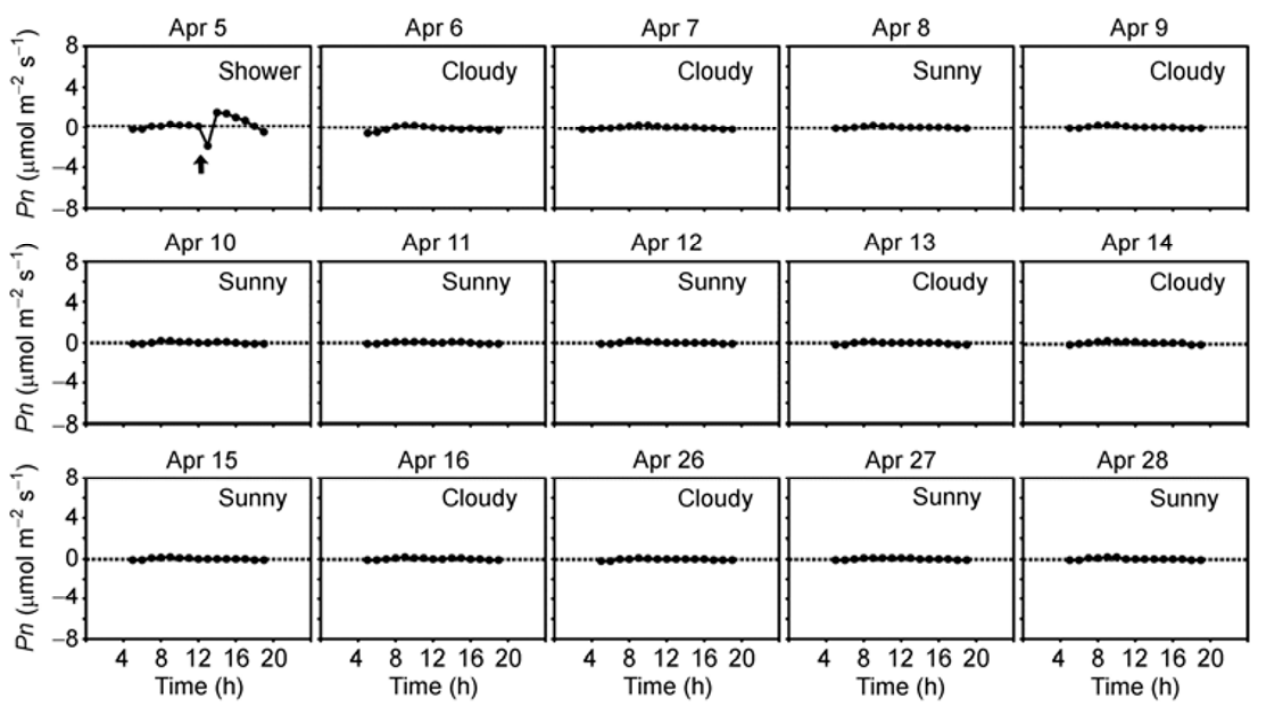

Figure 5 Field observations of the net photosynthetic rate (Pn) of Endocarpon pusillum at the CAS SDRS over the periods of April 5-16 and December $26-28$ in 2011. The arrows indicate rainfall events. 
There was a shower with a total precipitation of $1.0 \mathrm{~mm}$ on April 5, the first rain for 2011. Because of the rain, the carbon sequestration by $E$. pusillum was relatively high, at $85.2 \mathrm{mg} \mathrm{m}^{-2}$ in the two days after the spring shower. However, there was no rain for 10 days from April 7 to 16 and the total carbon sequestration was low, about $40.1 \mathrm{mg} \mathrm{m}^{-2}$ during these 10 days (Figure 6). The combined total carbon assimilation was $125.3 \mathrm{mg} \mathrm{m}^{-2}$ during the 12 days in spring.

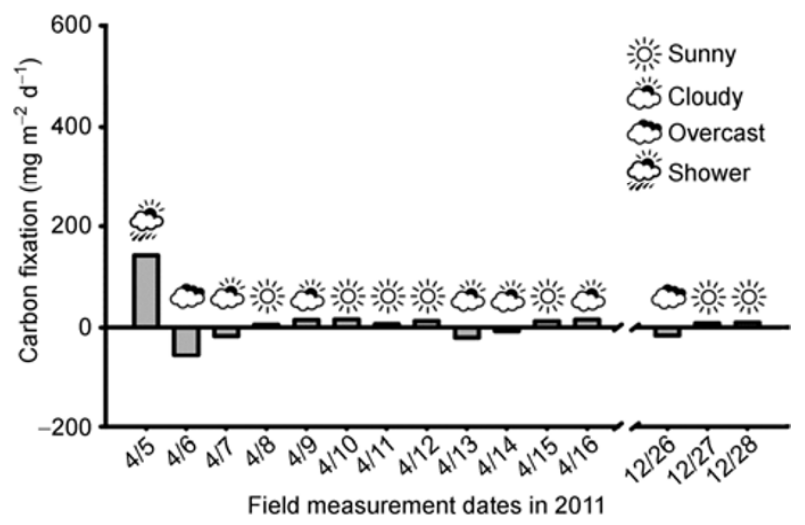

Figure 6 Field measurements of Endocarpon pusillum's daytime photosynthetic carbon intake over the periods April 5-16 and December 26-28, 2011 at the CAS SDRS.

Winter temperatures at the CAS SDRS are very cold and there is almost no precipitation. The carbon sequestration rates were $-16.7,8.1$, and $9.5 \mathrm{mg} \mathrm{m}^{-2}$ in the three days from December 26 to 28 , and the total carbon sequestration was only $0.9 \mathrm{mg} \mathrm{m}^{-2}$.

2.3 Respiration rate of $E$. pusillum in the dark under simulated conditions and the night respiratory carbon loss in the laboratory

Night respiration rate data were obtained in the laboratory under simulated conditions of rainfall, temperature and humidity. The simulated rainfall was given in the morning and the measurement was carried out at night.

When more than $2 \mathrm{~mm}$ of the simulated rainfall was given, the respiration rate of E. pusillum in the dark was $-1 \mu \mathrm{mol} \mathrm{m} \mathrm{m}^{-2} \mathrm{~s}^{-1}$ at $15^{\circ} \mathrm{C}$ on the night of July 10 only (Figure $7)$. However, negative $\left(-0.8,-0.5\right.$, and $-0.2 \mu \mathrm{mol} \mathrm{m} \mathrm{m}^{-2} \mathrm{~s}^{-1}$ at $5^{\circ} \mathrm{C}$ ) respiration rates were observed for three consecutive nights after the simulated rainfall on November 10 (Figure 7).

No obvious respiration was detected at night for E. pusillum when there was $0.5 \mathrm{~mm}$ of simulated rainfall on July 12 (Figure 7).

The software SigmaPlot 10.0 was also used to compute the nocturnal respiratory carbon loss. The results were then converted into mg C (Figure 8). When E. pusillum was saturated by spraying with water equivalent to $\geqslant 2 \mathrm{~mm}$ precipitation, the respiratory carbon loss was $343.5 \mathrm{mg} \mathrm{m}^{-2}$ after the simulated rain on July 10 . However, the total carbon loss was $463.5 \mathrm{mg} \mathrm{m}^{-2}$ in the three nights after simulated rain on November 10 (Figure 8).

\subsection{Estimating the annual carbon budget}

\subsubsection{Daytime photosynthetic carbon income ( $\Sigma N P)$}

The average monthly precipitation at the CAS SDRS was relative abundant $(>5 \mathrm{~mm})$ in the seven months from May to November during 2009-2011 (Figure 1). In these months, the lichen was relatively moist and the carbon assimilation was $2824 \mathrm{mg} \mathrm{m}^{-2}$ in the 25 days during June 30-July 8 and October 25-November 9 in 2010. Based on this number, the total estimated carbon assimilation was $24173 \mathrm{mg} \mathrm{m}^{-2}$ for the 214 days in the seven months from May to November (Table 1).

In the five months from December 2010 to April 2011, the average of monthly rainfall was little (Figure 1), and the lichen was dormant for much of the time in the relative dry
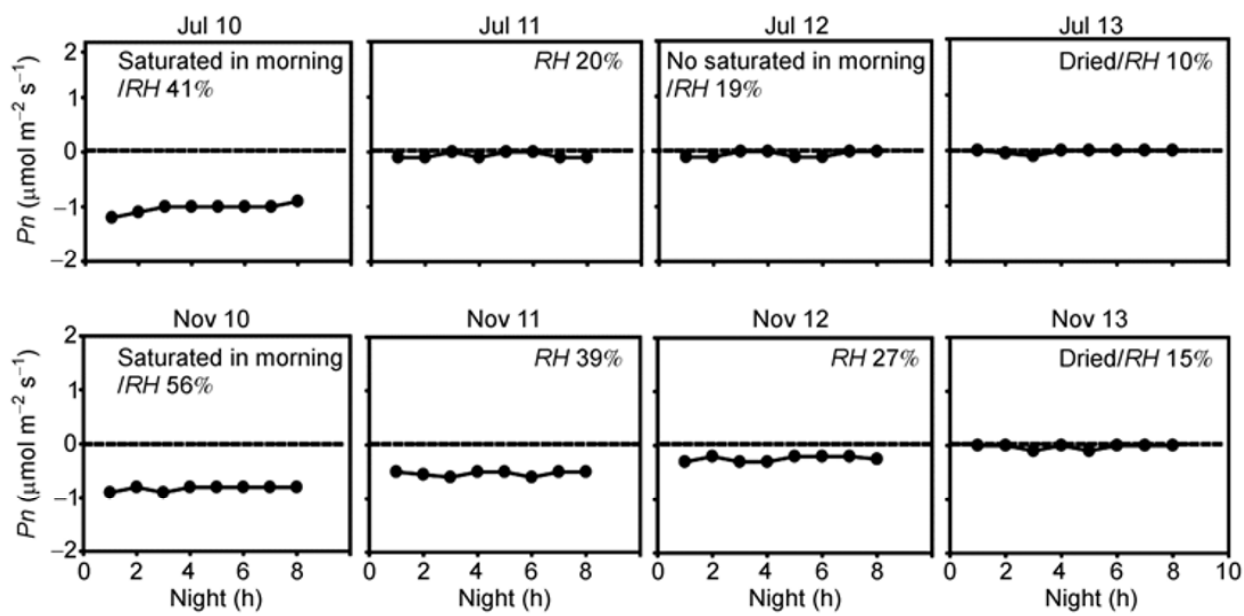

Figure 7 The nocturnal respiration rate of Endocarpon pusillum under laboratory simulated precipitation or dry conditions in July 10-13 and November $10-13,2010 . R H$ represents the relative humidity of the leaf chamber. 


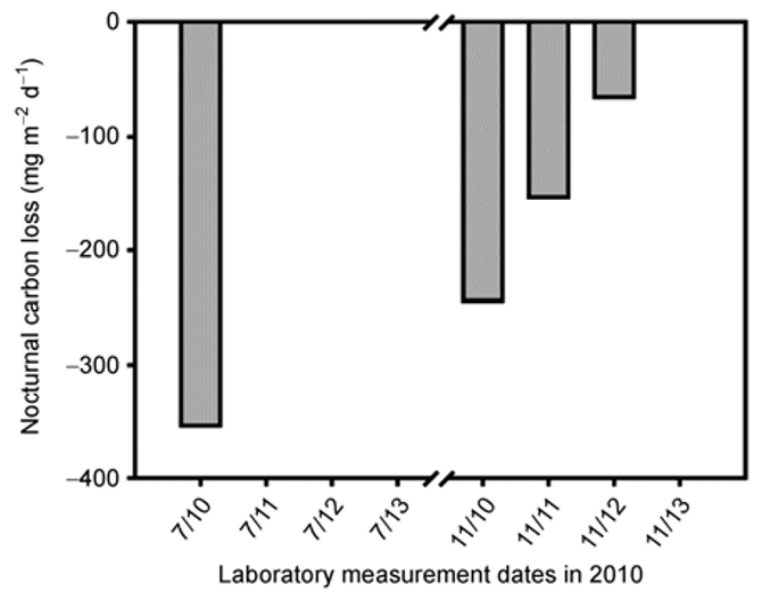

Figure 8 Endocarpon pusillum's nocturnal respiratory carbon loss under laboratory simulated conditions of precipitation or dry conditions over the periods of July 10-13 and November 10-13, 2010.

periods. During this period, the carbon assimilation was similar to that of the periods of April 5-16 and December 26-28 in 2011. Because carbon assimilation was $126.2 \mathrm{mg} \mathrm{m}^{-2}$ in the 15 days, the total estimated carbon assimilation would be $1270 \mathrm{mg} \mathrm{m}^{-2}$ for the 151 days in the five months from December to April (Table 1).

Altogether, the total carbon assimilation $\Sigma \mathrm{NP}$ was about $25443 \mathrm{mg} \mathrm{m}^{-2}$ per year.

\subsubsection{Nocturnal respiratory carbon loss ( $\Sigma D R)$}

According to the laboratory simulation experiments (Figures
7 and 8), the nocturnal carbon loss was $1271 \mathrm{mg} \mathrm{m}^{-2}$ during the period of June 30-July 8 and October 25-November 9 in 2010 at the CAS SDRS. During the 25 days, there were three rainfall events, one in the summer and two in the fall, each of which saturated the lichen thalli with water. Therefore, the carbon loss due to nocturnal respiration was 10880 $\mathrm{mg} \mathrm{m}^{-2}$ in the 214 days covering the seven humid months (Table 1). At the remaining nights the respiratory rates were weak and the carbon loss can be ignored. Based on these estimates, the E. pusillum annual nocturnal LDR was 10880 $\mathrm{mg} \mathrm{m}^{-2}$.

\subsubsection{Photosynthetic carbon budget $(\Sigma C)$}

Annual carbon gain is calculated according to the formula $\Sigma \mathrm{C}=\Sigma \mathrm{NP}-\Sigma \mathrm{DR}$ [22]. Because the annual $\Sigma \mathrm{NP}$ was 25443 $\mathrm{mg} \mathrm{m}^{-2}$ and the annual $\Sigma \mathrm{DR}$ was $10880 \mathrm{mg} \mathrm{m}^{-2}$, the net annual gain of carbon by E. pusillum was $14563 \mathrm{mg} \mathrm{m}^{-2} \mathrm{a}^{-1}$ (Table 1, Figure 9).

\section{Conclusion}

The results of the experiments show that the amount of carbon fixed by photosynthesis of the lichen E. pusillum at the CAS SDRS is $14.6 \mathrm{~g} \mathrm{~m}^{-2} \mathrm{a}^{-1}$. Thirty thousand square kilometers of sand dunes in the Tengger Desert could be turned into a carbon sink capable of fixing $438000 \mathrm{t}$ of carbon per year, if a Desert Biocarpet Engineering project could be carried out using the lichen E. pusillum.

Table 1 Annual Endocarpn pusillum carbon budgets divided into two groups according to the average monthly rainfall ${ }^{\text {a) }}$

\begin{tabular}{|c|c|c|c|c|c|c|c|c|}
\hline State & Field measured & Period (d) & $\mathrm{NP}\left(\mathrm{mg} \mathrm{m}^{-2}\right)$ & $\mathrm{DR}\left(\mathrm{mg} \mathrm{m}^{-2}\right)$ & $\Sigma \mathrm{SP}(\mathrm{d})$ & $\Sigma \mathrm{NP}\left(\mathrm{mg} \mathrm{m}^{-2}\right)$ & $\Sigma \mathrm{DR}\left(\mathrm{mg} \mathrm{m}^{-2}\right)$ & $\Sigma \mathrm{C}\left(\mathrm{mg} \mathrm{m}^{-2}\right)$ \\
\hline \multirow{2}{*}{ Relatively humid } & Jun. 30-Jul. 8, 2010 & 9 & \multirow{2}{*}{2824} & \multirow{2}{*}{1271} & \multirow{2}{*}{214} & \multirow{2}{*}{24173} & \multirow{2}{*}{10880} & \multirow{2}{*}{13293} \\
\hline & Oct. 30-Nov. 9, 2010 & 16 & & & & & & \\
\hline \multirow{2}{*}{ Relatively dry } & Apr. 5-16, 2011 & 12 & \multirow{2}{*}{126.2} & \multirow{2}{*}{-} & \multirow{2}{*}{151} & \multirow{2}{*}{1270} & \multirow{2}{*}{-} & \multirow{2}{*}{1270} \\
\hline & Dec. 26-28, 2011 & 3 & & & & & & \\
\hline Total & & 40 & 2950.2 & 1271 & 365 & 25443 & 10880 & 14563 \\
\hline
\end{tabular}

a) The field measurements include net photosynthesis (NP) and simulated nocturnal carbon loss (DR) and the similar period ( $\Sigma$ SP) to calculate the photosynthetic carbon income $(\Sigma \mathrm{NP})$, nocturnal respiratory carbon loss $(\Sigma \mathrm{DR})$ and total annual carbon budget $(\Sigma \mathrm{C})$.

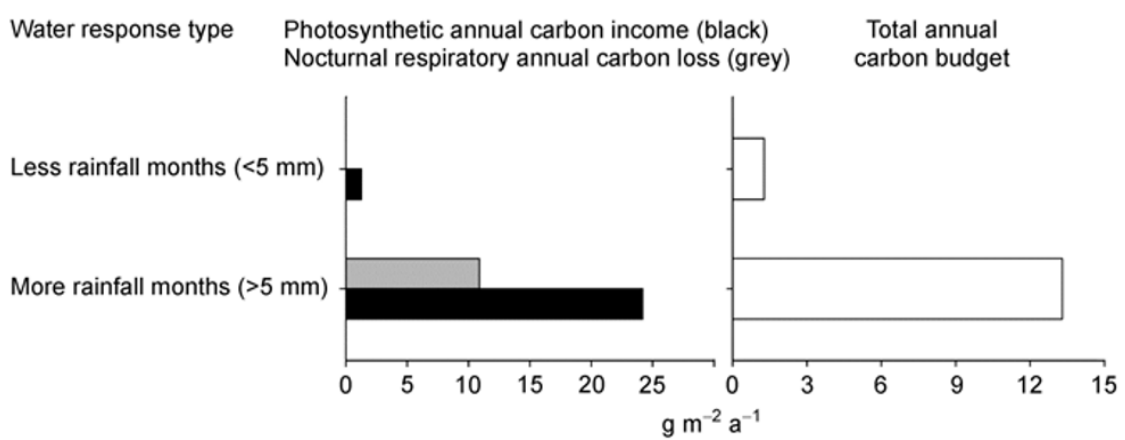

Figure 9 Endocarpon pusillum annual gain and loss of carbon, showing the contribution of the rainy months and dry months to the photosynthetic carbon income, nocturnal carbon loss and the carbon budget over a one-year period. 
We are grateful to the directors and the staff members of the CAS SDRS for their kind help during our work in the field, and for providing local weather data. Many thanks also go to Wang ChengChong of CAS SDRS, Liu Meng and Cao ShuNan of IM CAS for helping with our field measurements, and also Chen YanChang of Zeal Quest Scientific Technology Company for providing the opportunity to use the instrument for our experiments. This work was supported by the National Natural Science Foundation of China (31070018), the Knowledge Innovation Program of the Chinese Academy of Sciences (2010-Biols-CAS-0104) and Ministry of Science and Technology of China (2011BAC07B03).

1 Xiao H L, Li X R, Duan Z H, et al. Succession of plant-soil system in the process of mobile dunes stabilization (in Chinese). J Desert Res, 2003, 23: 605-611

2 Xiao H L, Li X R, Duan Z H, et al. Impact of evolution of plant-soil system on the water environment during the mobile dunes stabilization (in Chinese). Acta Pedo Sin, 2003, 40: 809-814

3 Long L Q, Li X R. Effects of soil microbiotic crusts on seedling survival and seedling growth of two annual plants (in Chinese). J Desert Res, 2003, 23: 656-660

4 Duan Z H, Xiao H L, Li X R, et al. Evolution of soil properties on stabilized sand in the Tengger Desert, China. Geomorphology, 2004, 59: $237-246$

5 Shi S, Ma F Y, Liu L C, et al. The effect on different vegetation structure to soil water contents in Shapoto region (in Chinese). J CUN, 2004, 13: 137-145

6 More W G. A Dictionary of Geography-Definitions and Explanations of Terms used in Physical Geography. London: Adam \& Charles Black, 1975

7 Wei J C. The Desert Biocarpet Engineering-A new way to control the arid desert (in Chinese). Arid Zone Res, 2005, 22: 287-288

8 Elbert W, Weberb B, Büdel B, et al. Microbiotic crusts on soil, rock and plants: neglected major players in the global cycles of carbon and nitrogen? Biogeosci Discuss, 2009, 6: 6983-7015

9 Ahmadjian V. The Lichen Symbiosis. New York: John Wiley \& Sons, 1993. $1-250$
10 Green T G A, Nash T H, Lange O L. Physiological ecology of carbon dioxide exchange. In: Nash T H, ed. Lichen Biology. 2nd ed. Cambridge: Cambridge University Press, 2008. 152-208

11 Farrar J F. The lichen as an ecosystem: observation and experiment. In: Brown D H, Hawksworth D L, Bailey R H, eds. Lichenology: Progress and Problems. London: Academic Press, 1976. 385-406

12 Seaward M R D. Contribution of lichens to ecosystems. In: Galun M, ed. CRC Handbook of Lichenology, Vol. 2. Boca Raton: CRC Press, 1988. 107-129

13 Nash T H, ed. Lichen Biology. 2nd ed. Cambridge: Cambridge University Press, 2008. 1-8

14 Palmqvist K, Dahlman L, Jonsson A, et al. The carbon economy of lichens. In: Nash T H, ed. Lichen Biology. 2nd ed. Cambridge: Cambridge University Press, 2008. 182-215

15 Lange O L, Meyer A, Zellner H, et al. Photosynthesis and water relations of lichen soil crusts: field measurements in the coastal fog zone of the Namib Desert. Funct Ecol, 1994, 8: 253-264

16 Li X R, Shi Q H, Zhang J G, et al. Study of plant diversity changes during the artificial vegetation evolution processes in the Shapotou region (in Chinese). J Desert Res, 1998, 18: 23-29

17 Li X R, Zhang J G, Wang X P, et al. Study on soil microbiotic crust and its influences on sand-fixing vegetation in arid desert region. Acta Bot Sin, 2000, 42: 965-970

18 Li X R. Influence of variation of soil spatial heterogeneity on vegetation restoration. Sci China Ser D-Earth Sci, 2005, 48: 2020-2031

19 Zhang T, Wei J C. Survival analyses of symbionts isolated from Endocarpon pusillum Hedwig to desiccation and starvation stress. Sci China Life Sci, 2011, 54: 480-489

20 Deason T R, Bold H C. Phycological Studies I. Exploratory Studies of Texas Soil Algae. Austin: University of Texas Publication, 1960

21 Ronen R, Galun M. Pigment extraction from lichens with dimethyl sulfoxide (DMSO) and estimation of chlorophyll degradation. Envir Exp Bot, 1984, 24: 239-245

22 Lange O L. Photosynthetic productivity of the epilithic lichen Lecanora muralis: long-term field monitoring of $\mathrm{CO}_{2}$ exchange and its physiological interpretation III. Diel, seasonal, and annual carbon budgets. Flora, 2003, 198: 277-292

Open Access This article is distributed under the terms of the Creative Commons Attribution License which permits any use, distribution, and reproduction in any medium, provided the original author(s) and source are credited. 